\title{
Effect of Play Way Method on the Numeracy Skills of Early Basic Education School Pupils in Ekiti State Nigeria
}

\author{
Dr. Abiodun A. Popoola \\ Department of Curriculum Studies, Ekiti State University, Ado-Ekiti, Nigeria \\ Email: popabiodun2013@gmail.com
}

Doi:10.5901/mjss.2014.v5n10p318

Abstract

This study investigated the effects of play-way method on the numeracy skills of early basic education pupils in Ekiti State, Nigeria. Play-way method has been described as the best method for enhancing pupils learning by many researchers. It was observed by the author that many teachers of early childhood education still use demonstration method to teach the pupils. An interview conducted by the researcher reveals that some teachers find demonstration convenient because they could not provide enough materials that will go round the pupils. The population of the study was all the early basic education schools in Ekiti State where pupils are given pre-primary education specifically, children between ages 4-5years. The sample is made up of 120 children split into two groups of 60. The design of the study was a quasi experimental. The children were interacted with for 6 weeks with the goals of exposing them to numerical literacy. Two groups were involved each exposed to different interactions, namely: guided play and demonstrations. The achievement test which is the instrument was validated and it has a correlation coefficient of 0.76 . The hypotheses tested the difference in the scores of the pupils in each group and also gender influence. The result showed that there was significant difference in the performance of students in favour of those in guided play group. Also gender has no influence on the pupils' achievement in each group. As a result of the findings, it was recommended that early child educators should use guided play with lots of activities to enhance pupils' achievement in numerical skills.

Keywords: achievement, guided play, demonstration, childhood education, numeracy skills, play-way method

\section{Introduction}

The early basic education is the education given in an educational institution to children prior to their entry into primary school. This type of education is a response to a change in the society. It has been observed by the researcher and stake holders in education that modern parents seem not to have adequate time to cater for their children at home because of the migration of working class women to urban towns. Also, these happen because most of the parents especially women have taken up paid jobs or are engaged in their own businesses, a situation which drastically reduces available time to cater for children at home.

In the traditional settings in Nigeria, young children below school age were usually left in the care of grand-parents but this has changed. The government took cognizance of this development and formulated a policy on early childhood education. The national Policy on Education (2009) states that the purpose of early childhood education shall be to:

i. effect a smooth transition from home to school;

ii. $\quad$ prepare a child for primary level of education;

iii. provide adequate care and supervision for the children while their parents are at work (on the farm, in the market and offices);

iv. inculcate social norms;

v. inculcate in the child the spirit of enquiry and creativity through the exploration of nature, the environment, art, music and playing with toys;

vi. develop a sense of cooperation and team spirit;

vii. learn good habits, especially good health habits

viii. teach the rudiments of numbers, letters, colours, shapes, forms through play.

The above forms the intent of government on the early childhood school education. 


\section{Literature Review}

Childhood education in its broad sense encompasses the years from birth to 11 years. It can be divided into three levels, namely:

i. early childhood- 0 to5 years

ii. mid childhood- 6 to 8 years

iii. late childhood- 9 to 11 years

At these levels children need more attention because these periods happen to be their formative years. In Nigeria, Ekiti- State in particular, the early childhood education has been left for the private sector for a very long time, the government started to develop interest in it about a decade ago. The major problem of the early childhood education in the hand of the private sector is the area of teaching with guided play which is usually ignored. This happens because some of the operators seem not to have adequate knowledge of what to do; those who have such knowledge seem to ignore it because of the cost, sacrifice and other high demand which early childhood education bears.

Onukaogu, Oyinloye and Iroegbe (2010) found that pioneers of early childhood education like Froebel, Montessori, Piaget, Vygotsky and John Dewey all believed that the preschool curriculum should be based on play way. For instance, Froebel in Essa (1999) believed that the child's natural unfolding occurs through play. Montessori in Essa (1999) advocated the interaction of the child with materials in a conducive environment for proper assimilation.

Pestalozzi who lived between 1748-1827 observed that if the child gains a good general education closely related in pleasures, duties, responsibilities and activities to a good home training and based on association with the social environment, the child will become fully developed, balanced, disciplined adult who will easily move out from its native society. Pestalozzi on numeracy wanted children to discover for themselves mathematical rules through activities specifically through plays.

Popoola (2008) in a study on sustaining children's interest in Mathematics found that the environment and activities provided for the children have influence on behaviour. She suggested that teachers should understand child development and provide most learning situations and materials in playful manners

\section{The Need for Numeracy Skills in Pre-Primary Schools}

The need for numeracy skills in the pre-primary education cannot be over emphasised. Numeracy skills are important aspects of literacy skills. Literacy skills such as listening, reading, writing speaking cannot be considered as complete without numeracy skills, such as : adding ,sorting by colours and by shapes. Moreover, research has shown that many students at post primary education levels performed poorly in numerical tasks (Oyinloye \& Oyedeji, 2011 and Popoola, 2010). This situation has been traced to deficient literacy skills at kindergarten level (Suporitz, Foley and Mishood, 2012)

The reason for this can be traced to poor foundation. Their interest might not have been aroused and sustained during their pre-primary education experiences. In most cases, they were not exposed to numeracy skills through play which is widely acknowledged as the best way children can learn. Teachers often introduce numeracy to the pupils through demonstration rather than involving them in the real activities through play. Children ought to be helped early enough to develop positive attitude towards numeracy because they will need to build their future academic attainments especially in Mathematics on the knowledge acquired during the preschool years.

Brottmiller (1999) in his study of early childhood education found that early childhood educator must provide good environment that will involve the pupils in play activities such as classification, seriation, numbers, time and space all which contribute to the gradual acquisition of mathematics concept. The early childhood classroom should therefore contain many materials that lend themselves to acquiring maths concepts. These include, blocks, sand and water implement. Oyinloye and Popoola (2013) in a study of activation of prior knowledge of pupils found that pupils' active participation in activities is essentials if pupils are to be actively involved in learning of math and English language. Oyedeji (1996) observed that pupil's feel more fulfilled when they are actively involved in the learning process. Brottmiller (1999) submitted that good early childhood programs not only improve the lives of the children and families involved but also result in substantial economic benefits for society. He went further to reiterate that although early intervention programs are expensive, their cost is more than recovered in subsequent years through greater schooling success, decreased need for special education, lowered delinquency and arrest rates, and decreased welfare dependence.

Barnett (2004) in his study of early childhood education found that preschool education helps to activate cognitive abilities. It also enhances school achievements, decrease level of failure and also build in children good classroom behaviour. All these are necessary in the promotion of numeracy skills. 


\title{
4. Learning through Play
}

Learning through play is a term that is often used in education and psychology to describe how children can learn to make sense out of the world around them. Children usually develop social and cognitive skills through play; they also mature emotionally and gain self-confidence which is a pre-condition to engage in new experiences. It is a general belief that plays enable children to make sense of their world. Also, it has been observed that utmost learning achievements occur while playing games because the environment is usually relaxed and learning becomes interesting and fun.

Learning through play is a group activity which involves males and females. There have been studies on the influence of gender on students' performances Babalola and Oyinloye, (2012) in a study titled gender distinctions found that male and female can perform well in language tasks not on the ground of gender but on the pedestal of individual ability. Kolawole, (2002) in a study on science found that there was difference between the achievement of male and female students in Science that is gender influences learning Sciences.

Maheshwari, (2013) found that, play offers informal and free atmosphere which gives the kids a chance to learn concepts, Mathematics and Language. He said visual materials can be used to teach the young ones about Mathematics, art and nature.

Play enhances motor expression which is learning by doing as against learning by rote, Onukaogu, Oyinloye and Iroegbu, (2010) found that play can help children to learn Mathematics in the following ways:

1. learn about equal lengths, open and close spaces, topography, solid geometric shapes as they play with blocks of different colours and shapes;

2. Learn about set theory as they group, sort and classify objects like abacus, counters, and mathematical shapes;

3. Learn to compare sets develop one by one correspondence, and solve problems using Mathematics( such as counting the pieces needed for each to play a game);

4. Learn to recognise, duplicate and extend simple patterns using a variety of materials;

5. Increase abilities to match, sort and put in a series, and regroup objects according to one or two attributes such as shapes or sizes;

6. Begin to recognise, describe, compare and name common shape, their parts and attributes;

7. Progress in the ability to put together and take apart shapes;

8. Develop increasing ability to count in sequence to 10 and beyond.

The type of play that is considered most suitable for children to learn Mathematics is guided play. This requires that a teacher using this method, has to plan his lesson, decide on the activities that the children will perform, decide the role of the teacher and the learning outcomes. The following are the examples of the guided play:

\section{Teacher's Activities}

Guide the children to count small objects in turns. For example, teacher asking David to put a pencil on the table, ask how many pencils are on the table?

\author{
Class: One pencil \\ Teacher Agnes to add one pencil, how many pencils are on the table class? \\ Class: Two pencils \\ Teacher: James add one pencil, how many all together? \\ Class: Three pencils \\ Teacher: Jane add one pencil, how many are now on the table class? \\ Class: Four pencils. \\ Teacher: Class count together, one, two, three, four. \\ Teacher: Jane, count the pencils on the table
}

\section{Counting in Groups and Arranging in Sequence}

\section{Teachers' Activities}

Teacher: Lead each child to arrange the objects/ apparatus to show that each row is one more than the next

Class activities: Each pupil arranges the shapes according to their understanding while the teacher correct them. 


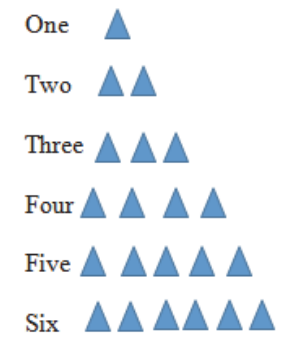

Teacher: ask each child to drop an object into a box in turns and count e .g, first child, one, second child, two Teacher: asks the pupils to arranging the objects as they count to show the number counted
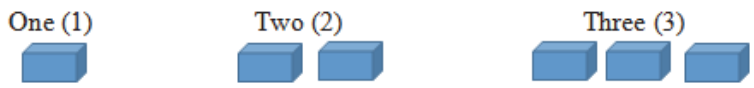

Other Activities that Can Enhance the Learning of Mathematics in the Pre-Primary Schools are Listed Below

i. Songs

ii. $\quad$ Chart

iii. $\quad$ Picture etc

1. Song/Rhyme: This can be used to teach numbers since pupils learn in a play way method which enhances recall and easy recollection of activities in the class. These are fun activities.

2. Chart: We can use this to teach comparison of sizes such as height, weight.

3. Picture: Pictures can be used to teach numbers and operations like addition and subtraction. This encourages the child's reasoning, thinking and increase the child's pursues and enquiries.

4. Use of cartoons: the use of cartoons can interest early pupils and advantage can be taken of this to teach mathematics. Cartoons are diagrammatic images representing children playfully teaching mathematics to each other.

5. Counters: This may be sticks, pencils, straw, pebbles, chalk stick etc. Pupils can use them to sing numbers to enhance value, identification, reading and writing skills.

6. Number balls: We use mouse to click on the balls in ascending order of numbers.

7. Counting cubes: Pupils will input numbers by clicking the number button or by pressing number keys.

8. Arithmetic game: Click on numbers to complete the equation at the button, this can be used for higher school children/students.

9. Mathematics lines: Destroy balls by forming pairs that add up to 10 . You can use one ball to destroy a group of same numbered balls;

10. Tritris: Destroy blocks by forming complete rows with the blocks;

11. Numbers: The aim of the game is to clear the playfield making a necessary sum of numbers on neighbouring tiles.

12. Number selector: A clear way of generating one and two-digit numbers, using fish as put up by Julie Rance.

13. Number hats: A fantastic idea for developing number bonds and many other Mathematics concepts. Children can sort the hats by colour, shapes and size.

14. Sports ladders: A fun mathematical activity which take advantage of children's interest in sport.

15. Measurement Guide: A handy printable document with information about different units of measurement and conversions between them. Mike Walker was of the opinion that measurement guide helps children to coordinate hands.

[Retrived from http://www.primarygames 11/02/14 http://www.teachingideas.]

Guided play is a means of engaging the pupils in activities that will enlist their interest in learning. The thrust of the study is to find out if there will be differences in the performance of children taught with guided play and demonstration methods in mathematics. 


\section{Rationale for the Study}

The author has observed that many early childhood Mathematics teachers teach their children using demonstration method which did not usually involve children in playing or performing activities other than answering questions asked by their teachers. It was also observed that many teachers when using demonstration method did not usually provide enough materials which could give their students opportunities to work with the materials and to have full participation.

\section{Research Questions}

Two research questions were raised for the study:

i. Will there be any difference in the achievement of children taught with guided play and demonstration methods in Mathematics?

ii. Will there be any difference in the achievement of male and female children taught with guided play and demonstration methods in Mathematics?

\section{Research Hypotheses}

Two research hypotheses were generated from the research questions

1. There will be no significant difference between the achievement of children taught with guided play and demonstration methods in mathematics?

2. There will be no significant difference between the achievement of male and female children taught with guided play and demonstration methods in mathematics?

\section{Purpose of Study}

This study investigated the effects of guided play and demonstration methods on the numeracy achievement of early basic education children. The study intends to find out which of the methods will enhance pupils numeracy skills in basic education

\section{Research Instrument}

The research instrument was an achievement test based on the numerical skills in early basic education Mathematics syllabus. The instrument contains counting, arrangement of blocks to match number, arrangement by shapes and number, putting blocks together and taking apart. The instrument was validated by specialist in curriculum studies. The reliability was established through test and retest methods. The data collected during the test for reliability which involved 20 pupils who were taught for three weeks was subjected to Pearson's product moment correlation statistics. The result yielded a correlation coefficient of 0.70 which was found to be significant enough.

\section{Method of Study}

The design of this study is quasi-experimental. It involved two experimental groups: guided play and demonstration method groups. The population of the study is the early basic education section in all the primary schools in Ekiti State. Specifically, children ages between 3 and 4 years. Four schools were selected where 120 children were picked as samples. The samples were further divided into 2 equal groups through random selection, with each group comprising 30 males and 30 female children.

\section{Experimental Procedures}

The researcher trained the early education teachers who were interested in the use of the instruments and the study. The teacher in turn taught the children for six weeks. Two schools were used for guided play with sixty pupils while another two schools were used for demonstration method. The data collected were collated and subjected to t-test statistics and decision taken at 0.05 level of significance.

\section{Results}


Table 1: t-test summary for difference between guided play group and demonstration group

\begin{tabular}{|c|c|c|c|c|c|c|c|}
\hline Source of Variation & $\mathbf{N}$ & Mean & Std & df & t.cal & t-table & Remark \\
\hline Guided Play & 60 & 22.61 & 1.96 & \multirow{2}{*}{59} & \multirow{2}{*}{6.53} & \multirow{2}{*}{2.00} & \multirow{2}{*}{ Significant } \\
\hline Demonstration & 60 & 18.61 & 3.7 & & & & \\
\hline
\end{tabular}

The table above showed that $t$-cal was 6.53 while table value was (2.00). t-calculated was greater than the table which means that there is significant difference.

Table 2: t-test summary for difference between achievement of male and female pupils in guided play

\begin{tabular}{|c|c|c|c|c|c|c|c|}
\hline Source of Variation & N & Mean & Std & df & t.cal & t-table & Remark \\
\hline Guided Play & 30 & 22.20 & 0.99 & \multirow{2}{*}{29} & -1.57 & \multirow{2}{*}{2.047} & \multirow{2}{*}{ Not Significant } \\
\hline Demonstration & 30 & 22.96 & 2.57 & & & & \\
\hline
\end{tabular}

The table above shows that the t-calculated is less than the table value which is an indication that there is no difference between the achievements of pupils taught with guided learning method. The mean score shows a little difference which is not significant.

Table 3: t- test summary for difference between the achievement of male and female pupils taught with demonstration method

\begin{tabular}{|c|c|c|c|c|c|c|c|}
\hline Source of Variation & $\boldsymbol{N}$ & Mean & Std & $\boldsymbol{d f}$ & $\boldsymbol{t}$.cal & $\boldsymbol{t}$-table & Remark \\
\cline { 1 - 6 } & 30 & 18.76 & 3.91 & \multirow{2}{*}{29} & -0.392 & \multirow{2}{*}{2.046} & \multirow{2}{*}{ Not Significant } \\
\hline Demonded Play & 30 & 19.06 & 3.59 & & & & \\
\hline
\end{tabular}

The table above shows that the t-calculated is less than the table value which is an indication that there is no difference between the achievements of male and female pupils taught with guided learning method and demonstration method.

\section{Discussion}

The data analysed in respect of hypothesis one which tested the difference in the achievement of pupils showed that children taught with guided play have the higher mean scores. This by implication indicates that they performed better than those taught with demonstration method. The hypothesis tested showed that there is significant difference in the performance of the children in the two groups. The findings of this study buttresses Onukaogu, Oyinloye, Iroegbu, (2010) who cited the pioneer of early childhood education such as Frobel, Montessori and Vygolsky all who propounded that children should be taught through play.

The second hypothesis which tested the difference between the achievement of male and female in each of the methods showed that there was no difference between the achievement of the male and female pupils in each of the methods. This findings supported the findings of Oyinloye \& Babalola (2012), Ayodele \& Popoola (2006) and Popoola (2004) that male and female pupils can perform well without disparity if they were exposed to the same condition. Also, the study however contradicts Kolawole (2002) and Popoola (2008) that gender has influence on students learning in Science and Mathematics. The study showed that gender has no influence on the learners taught with guided and demonstration methods. The findings showed that guided method has similar effect on enhancing both male and female to learn numeracy skills in early childhood education. The findings also showed that demonstration method has the same effect on the achievement of early primary school pupils in numeracy skills.

These findings on gender corroborates the findings of Babalola \& Oyinloye (2012) who found that male and female can perform well in language task not on the basis of gender but on the pedestal of individual ability and materials available. 


\section{Conclusion}

The study had investigated the teaching of numeracy skills to early basic education pupils and found that the use of guided play was better than demonstration method. The study concluded that guided play which involves a lot of activities is better than demonstration methods. Guided play leads to child centred approach while demonstration would be seen as teacher centred. Children in early basic education should be exposed to a lot of activities in a play way form

\section{Recommendations}

As a result of the findings of the study, it is recommended that children in the early basic education should be taught with guided play because it exposes and involves the pupils in playing and performing same activities. It is a child centred method which is capable of enlisting the pupils' interest in learning. This study has proved that guided-play method is good for both male and female.

\section{References}

Ayodele, J. B.; Popoola, A. A. \& Akinsola, M. K. (2006). Gender analysis of students'enrolment and academic staff in the University of Ado Ekiti, Nigeria. The African Symposium: Journal of African Educational Research Network, 6(3\&4): 47-55. ISSN TX6-342323.

Babalola. J. O. \& Oyinloye, G.O (2010). Language and gender distractions.

Barnett, S. (2004). The value of effective preschool education. New York National Institute of Early Education Research.

Essa, E.(1999). Introduction to early child education, 3 $3^{\text {rd }}$ Edition, London:Delmar Publishers

Downey, S.; Hares, B.O. \& O'Neil, B (2013). Centre for Social and Educational Research. Dublin Institute of Technology office of the Minister for Children.

Brottmiller, E. (1999). Introduction to childhood education instructor's annotated edition. Eva Essa-3rd.Ed. United States.

Kolawole, E. B. (2002). Sex difference in academic achievement in science subjects in Nigerian tertiary institutions. Research in Curriculum Studies (RICS). University of Ado-Ekiti. 2(1): 168-173.

Maheshwari, V. K. (2013). Froebel: The play-way method. Permalink concept of environment. India.

Oyedeji, O. A. (1996). Assessment of gender factor in science and mathematics texts in Nigeria. Zimbabwe Journal of Education Research. 1: 45-53.

Onukaogu, C. E.; Oyinloye, G. O. \& Iroegbu. V. I. (2010). A capacity enhancement workshop training manual for early child care and development education teachers. Ikeji-Arakeji: JABU.

Oyinloye, G. O. \& Adeleye, L. (2010). Impact of media of senior secondary school students perfomance in speech work in English language in academic leadership. The Online Journal. 8(4). Effort Hays State University.

Oyinloye, G. O. \& Babalola, J. O. (2012). Language and gender distinction. International Review of Social Sciences. 2(2).

Oyinloye G.O \& Popoola, A. A (2013) Activating Junior Secondary School Students Prior Knowledge for the Development of Vocabulary, Concepts and Mathematics through Instructional Strategies. International Journal of Education and Literacy Studies (IJELS), 1(2), p.1-7, Australian International Academic Centre, Australia

Popoola, A. A. (2003). Gender difference in Nigeria. Research in Curriculum Studies (RICS). 2(1): 37-44.

Popoola, A. A. (2008). Sustaining children's interest in mathematics via interactive activities. The Social Sciences. 3(2): 66-72. Medwell Journals.

Popoola, A. A. (2009). Influence of gender and classroom climate on secondary school students' achievement and mathematics related subject in Ekiti State. Benin Journal of Gender Studies. 1(2): 129-137. Centre for Gender Studies, University of Benin.

Popoola, A. A. (2004). Evaluation of primary boy's and girl's interest in science. International Journal of Children-in-Science and Technology (CIST). 2(1): 48-52. A publication of Children-In-Science and Technology.

Suporitz,J. Foley, E. \& Mishook, J.(2012).In search of leading indicators in education. Education Policy Analysis Archives, 20(19),. Retrieved (Dec. 2013). From http:// epaa,,asu, edu/ojs/article/view/952

Qadiri, F. \& Manhas, S. (2009). Parental perception: Towards pre-school education imparted at early childhood education centres. Journal of Studies of Home, Community Science. India: KamRaj.

UNESCO (1994). A means for empowering girls and women. Contribution of UNESCO to the 1994 world survey on the role of women in development. 